\title{
Critically Analyse the Role of Senior Managers as Barriers to Organizational Change and Explore How this can be Addressed
}

\author{
Jeton Zogjani, M.Sc \\ zogianijeton@gmail.com \\ Samed Raçi, M.Sc \\ samed.raci@gmail.com
}

\begin{abstract}
:
In this research papers is analyse the critically role of senior managers on organizational change and how their role can be addressed in the best and appropriate way in organizational change. Organizational change can achieve through effect of behaviour on organizational performance as well as role and responsibility that senior managers have on motivation within organizational changes. In some cases senior managers during process of organizational change create barriers for any group of interest within organisation. The managerial decisions in the process of organizational change are associated with conflict and it can be from internal and external environment. Managerial decisions may affect the interest of internal groups in organization and senior managers need to their authority to resolve the conflict situation in organization. Internal conflict usually is associated with poor decisions, administrative allocation and latent roles while most of external conflicts are from technology and environment change. In modern economy, the nature of organizational change and behaviour has their impact from different factors, such as: rapid change of technology, competitions, market change and environment change.
\end{abstract}

Keywords: effective decisions, motivation, organizational behaviour, organizational conflict, performance

\section{Introduction:}

The purpose on this research paper is to explain role of senior managers on organizational change, their role as possible barriers on organizational change and how can be addressed in the best way. Therefore the role of senior managers is essential in organizational change because the main responsibility of senior managers is to increase interest of understanding as well as encouraging of knowledge-sharing behaviour in their organizations, by Lin \& Lee (2004). While one the most challenge in the managerial world is organizational change because the change comes for internal and external environment and that can often appear as a serious barrier. In the first part is elaborated managerial behaviour with their employees within organizational and environmentally change, process of understanding, implementing behaviour as a related process for management.

Also is discussed effect of behaviour on performance of organization, role and responsibility of the senior managers to increase motivation on organizational behaviour. In second part is elaborated managerial conflict in organization, when the conflict in organization appears in different form, it comes from internal group and environment which is really challenge for managerial decision. To resolve conflict in their organization, senior managers with their authority have to resolve these conflict situations. In the last part are analyzed importance of change and the role of management in process of change, the way how they address the issue in the process of change, which of them can be more adapt in organizational and environment change. Their action in these situation of change, may have positive (or negative) to increase performance for employers and for their organization.

\section{Literature Review:}

The world of organizations is a messy one which is full of controversies and most of them appear as irresolvable, as argue Thomas, (2003). Despite these circumstances, the managerial behaviour and organizational change have shown a high number (over $70 \%$ ) of failures of organizations then these data shown how is important the role of senior managers toward changes in their organization. Environment (external) of organization has rapidly changed and where the organization has 
their delay on change, it will affect on organizational behaviour in whole organization. So, it is main argument that organizational change should be process of change. According by Buchanan \& Huczynski (2010) the organizational change is interdisciplinary field which research the behaviour people within organization as well as environment and change behaviour. While the role of organizational behaviour is an actual performance of a position or organizational responsible, as cited by Teh \& Yong (2011)

To understand organizational behaviour is not easy process for managers also to implement the behaviour inside of organization is very difficult process for managers. But where senior management has reached their intention for good organizational behaviour, their success is inevitable and this can achieve by different ways. Organizational performance always has been associated with success while organizational culture has been positive line with results of effectiveness, as argue Vallett (2010). According by D'Aquila (2001), the main role of senior management is to create the ethical behaviour. Senior management with behaviour change tends to promote growth performance, this can be achieving through team training and the eternal management challenge, Prokech (2009).

If the senior management can't create a good environment on organizational behaviour, it immediately will present as internal problems at all organizational levels. If referred Suazo \& Stone-Romero (2010) such behaviour directly will have impact on work satisfaction, courtesy, dedication and organizational commitment; and they are related negatively on role performance and organizational behaviour. According by Snape \& Redman (2010), employee behaviour may have implications for organizational performance. The negative behaviour may present problems or barriers that nobody in the organization doesn't want to happen (as individual or as organization). In these situations the role and responsibility of senior management is to increase motivation on organizational behaviour. Good results on organization reflect to job satisfaction and positive organizational behaviour, and in shaping employee attitudes, beliefs, and behaviours, Morin et al (2010) \& Chiaburu et al (2010).

Senior management always should aim to establish a fair treatment, such as: cultures, nature of organizational behaviour, accompany the behavioural in the workplace that can positively influence in change behaviours and minimize anti-change on organizational behaviour, based by Fuchs (2010). The senior management role is necessary to create organizational behaviour to be supported with organizational policies in order to exceed the potential problems. As argued by Aryee et al (2004), concepts of organizational politics need to be connected with employee attitudes and behaviour in the organization, and good organizational behaviours have positive effect so employees increase trust in their managers. According by Korsgaard et al (2002) in managerial behaviour are five categories that may affected on their employees behaviour and they are as following: consistency, integrity, control, communication and demonstration of concern. This is what every manager wants to be on their organizational behaviour.

Different circumstances often can bring organizational conflict but this is not the desire of senior management. According by Bakhare R. (2010), conflict can arise for various reasons and conflict may result from not compatible between individuals or groups for different issues, such as: needs and belief, etc; while on organizational aspect conflict can be expect individuals and groups also in organizational level. Conflict usually is associated with effective decisions, and relationship conflict is associated with poor decisions, as cited Tony \& Peterson (2000). Organizational conflict displayed for some reason which can be internal conflict that mostly arises from organizational change and external conflict usually comes from environment change. According by Thomson (1960) conflicts within organization is administrative allocation and latent roles while external conflict is from technology and environment change. Role of senior management is to resolve these conflicts through conception and principles of organization. In the other side external effects very easy can bring conflict in the organization.

If have the situation that senior manager is powerless with his authority during time of conflict in organizational, then the unresolved conflict may create a higher negative effect on organization and on employees behaviour. According by Lieberman et al (2009), unresolved conflict will be reflected in many aspects and it will have effect particularly on: poor decision-making, cost time, decline of motivation for work and legal costs, etc. As argue by Butt et al (2009), the high level of conflict inside of organization has insupportable impact on the employee performance. This would reflect a poor level of performance for senior manager as well as for the organization; this is a situation where the senior manager's role is small against conflict situation and very inappropriate situation during organizational change.

To eliminate these barriers should be strengthened role of senior manager through control continuous in the process of organizational change. According by Samoilenko (2008), control is associated with an order and absence of the conflict 
while an absence of control is associated chaos in organization and presents the conflict. As argue by Shock et al (2005), the wider and actively implication of management, is the most important component to managing conflict within the top management group. Thus, the role of senior management is constantly to approach in solving problems and eliminating barriers if these appear during their activity in organization. According by Ohbuchi \& Mariko (2003), the present results suggest that the management contributes to the constructive settlement on organizational conflict. This is the best way to address the issue in resolving conflict during the process of organizational change.

The way how is addressed the issue of change, belongs if only compare the role of leadership and top level management in the change process, because today the change is rapidly in many aspects: technology, competitions, change market and environment change. Therefore, as cited by Bernard (1996), the ability to manage change in now recognized as a core organizational competence. According by Nadkarn \& Mohammed (2011), these challenges require careful management of temporal resources in teams. According by Grabt et al (2011) is essential to understand how characteristics leader may affect group performance on change environment. While the characteristics of management are to keep control the good performance. According by Gill (2003), when workers have more control, it can help define their own goal and them enables to participate in decision making about their job satisfaction. The manager's work is to reflect in satisfy the group's needs and realization of organizational goal.

Despite the way, how addressed issues over the role of managers in process of change which is very big as well as not easy to keep control organizational system during organizational change; therefore required repeatedly commitment and force. As argued by Mitzberg (1973), high levels of management have many roles in process of organisational change but the main are in following: interpersonal, information and decisive. Many authors have discussed that without management don't have organizational work while mangers are always needed, (Weihrich \& Koontz (1993)). Therefore senior manager can increase their performance by support their group in the different way e.g. through high level motivation, good communication, creative ability; as cited by Bernard (2009). Ethics is very important tool in the management of organizations and in underlying values of individuals, groups and organizations. It has a significant impact not only on organizations environment but also on society as a whole. Finally, positive results of organizational change are to create ethical behaviour in organization, to facilitate adaptation on environment change, then to reduce conflict in organization. When senior manager have achieved this high level of performance, they will called first class worker, Taylor (1947)

\section{Conclusion:}

In conclusion is discussed the definition of the role of senior manager by different authors and their responsibility during the organizational change. The role of senior managers is necessary in many areas, such as: in develop skills, good organizational behaviours and provide problem solving in decision making. They facilitate successful progress in organizational change and the organizational change depend directly by value, experience, motivation, and beliefs of senior managers, as cited by Meneto et al (2002), Price (2004) \& Lin (2007). Environment (or external) change reflects in organizational change then these changes have affects in all level of managers and to their employees. Process of organizational change often describes as difficulties process but the role and responsibility of senior managers is to exceed these barriers (or difficulties). In a changing world, managers should promote stability, control and problem solving during process of organizational change, as argued Kotler (2001). Behaviour in the organization may be displayed in different way, in fact, this can derived from the external environment to inside organizational behaviour.

Therefore senior manager need to create ethical behaviour and motivation in order to adapt easily environmental change in organization. If the senior managers can't adapt organizational change and appropriate organizational behaviour in organization, it will appear organizational problems at all level of organization. Organizational behaviour need to be supported by organizational policies to exceed the potential problems. There are five characteristic which have their effect on managerial behaviour, such as: behavioural consistency, integrity, control, communication and demonstration of concern and their impact is to increase trust of workers to their managerial level. Organizational conflict may be test for managers during their activity. Conflict can come from inside organization, such as: between managers' level, individuals or groups, etc. Managers are responsible to resolve these conflicts through conception and principles that have their organizations. External factors that may create organizational conflict within organization are technological change and environmental change and these both factors may pushes managers to make decisions which may arise conflict within the organization. The best way to eliminate conflict in organization is control and wider implication of senior managers in managing conflict. 


\section{References}

[1] Aryee et al (2004). Exchange fairness and employee performance: An examination of the relationship between organizational politics and procedural justice, Organizational Behaviour and Human Decision Processes, 94 (1), pp. $1-14$

[2] Bakhare R. (2010). The Manager and Conflict Management, SCMS Journal of Indian Management, 7 (4), pp 41 57.

[3] Burnes, B., (1996). "No such thing as ... a "one best way" to manage organizational change", Management Decision, 34 (10), pp. 11 - 18

[4] Buchanan D.A. \& Huczynski A.A. (2010). Organizational Behaviour, $7^{\text {th }}$ ed. London: Pearson Education Ltd. p. 6

[5] Burns B (2009). Reflections: Ethics and Organizational Change - Time for a Return to Lewinian Values, Journal of Change Management, 9 (4), pp. 359 - 381

[6] Butt et al (2009). An Investigation of Intergroup Conflict and Its Impact on Employees Performance in Pakistani Banking Sector, South Asian Journal of Management, 16 (1), pp. 92 - 101

[7] Chiaburu et al (2010). Social and Economic Exchanges with the Organization, Leadership \& Organization Development Journal, 32 (5), pp. 442 - 461.

[8] L'Aquila J.M., (2001). Financial Accountants Perceptions of Management's Ethical Standards, Journal of Business Ethics, 31 (3), pp. 233 - 244

[9] Fuchs S. (2010). The impact of manager and top management identification on the relationship between perceived organizational justice and change-oriented behaviour, Leadership \& Organization Development Journal, 32 (6), pp. $555-583$

[10] Gill R. (2003). Change management or change leadership, Journal of Change Management, 3 (4), pp. 307 - 318

[11] Grabt et al (2011). Reversing the extra leadership advantage: the role of employee proactive, Academy of Management Journal, 54 (3), pp. 528 - 550

[12] Korsgaard et al (2002). Trust in the Face of Conflict: The Role of Managerial Trustworthy Behaviour and Organizational Context, Journal of Applied Psychology, 87 (2), pp. 312 - 319

[13] Lee G.G. \& Lin H.F., (2004). Perceptions of senior managers toward knowledge-sharing behaviour, Management Decision, Journal of Management History, 42 (1), pp.108 - 125

[14] Lieberman et al (2009). Designing an Internal Organizational System for Conflict Management, Dispute Resolution Journal, 64 (2), pp. 62 - 74

[15] Mitzberg H., (1973). The Nature of Managerial Work, New York: Harper and Row

[16] Morin et al (2010). Affective Commitment and Citizenship Behaviours Across Multiple Foci, Journal of Managerial Psychology, 26 (8), pp.716 - 738

[17] Nadkarn S. \& Mohammed S., (2011). Temporal Diversity and Team Performance: the Moderating Role of Team Temporal Leadership, Academy of Management Journal, 54 (3), pp. 489 - 508

[18] Ohbuchi K. \& Mariko S., (2003). Three Dimensions of Conflict Issues and their Effects on Resolution Strategies in Organizational Change, International Journal of Conflict Management, 14 (1), pp. 61 - 73

[19] Prokech S. (2009). How GE Teaches Teams to Lead Change, Harvard Business Review, 87 (1), pp. 99 - 106

[20] Samoilenko S. (2008). Fitness Landscapes of Complex Systems: Insights and Implications On Managing a Conflict Environment of Organizations, Emergence: Complexity \& Organization, E: Co, 10 (4), pp. 38 - 45

[21] Shock et al (2005). The "What" in Top Management Group Conflict: The Effects of Organizational Issue Interpretation on Conflict among Hospital Decision Makers, Journal of Managerial Issues, 17 (2), pp. 162 - 177 
[22] Simons, T.L. \& Peterson R. S., (2000). Task conflict and relationship conflict in top management teams: The pivotal role of intergroup trust, Journal of Applied Psychology, 85, pp. 102 - 111

[23] Snape E. \& Redman T., (2010). Organizational Citizenship Behaviour, and Performance: A Multi-Level Analysis, Journal of Management Studies, 47 (7), pp. 1219 -1247

[24] Suazo M.M. \& Stone - Romero E.F., (2010). Implications of psychological contract breach: A perceived organizational support perspective, Journal of Managerial Psychology, 26 (5), pp. 366 - 382

[25] Taylor F., (1947). The principles of Scientific Management, New York: Harper and Row

[26] Teh P.L. \& Yong CH.CH., (2011). Knowledge sharing in is personnel: Organizational Behaviour's perspective, Journal of Conformation Systems Computer In, 51 (4), pp. 11 - 21

[27] Thomas, A.B., (2003). Controversies in Management: Issues, Debates, Answers, $2^{\text {nd }}$ ed., London: Rutledge

[28] Thomson J.D., (1960). Organizational management of conflict, Administrative Science Quarterly, 4 (4), pp. 389 - 409

[29] Vallett C.M., (2010). Exploring the Relationship Between Organizational Virtuousness and Culture in Continuing Higher Education, The Journal of Continuing Higher Education, 58, pp.130 - 142.

[30] Weihrich H. \& Koontz H., (1993). Management: A Global Perspective, Singapore: McGraw-Hill 